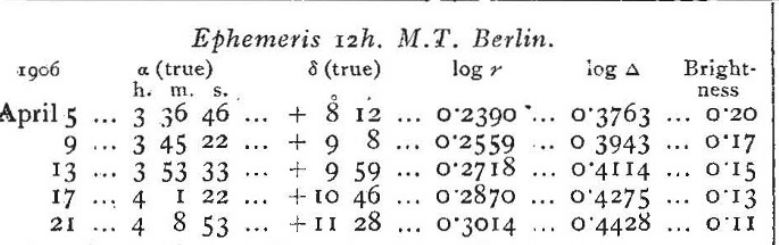

An observation at Strassburg on March 17 gave corrections of $-\mathrm{x} x \mathrm{~s}$. and $-3^{\prime} \cdot 9$ to this ephemeris. The comet was pale, with no certain nucleus, and the ill-defined nebulosity was about $2^{\prime}$ in diameter; total magnitude about $\mathrm{YI} \cdot 5$.

This faint object is now apparently traversing the constellation Taurus towards the Pleiades, and will be some $3^{\circ}$ south of that asterism on April 23. It sets, a little to the N. of W., at about 9 p.m.

A Systematic Study of Faint Stars.-Apropos of Prof. Kapteyn's plan for studying faint stars, Prof. Pickering gives a detailed account of how similar work is being performed at Harvard College Observatory in Circular No. 108.

It is impossible to describe the whole work here, but both photometric and photographic methods are being employed, and by using the two 24 -inch reflectors Prof. Pickering hopes to extend the survey to stars fainter than Phœbe.

In studying the spectra, the 8-inch Draper and Bache telescopes have been employed, and stars down to the eleventh magnitude have been observed successfully. Using the 24 -inch reflectors, Prof. Pickering hopes to photograph the spectra of much fainter stars.

By following the stars precisely, so that the resulting spectrum is merely a line, thirteenth magnitude stars have been dealt with, and, on a photograph obtained with the 8-inch Draper telescope, the spectrum of a star of mag. 13.3 is sufficiently clear to be classified; the same plate shows the spectra of $x$ Io stars within $I^{\circ}$ of the North Pole.

Stars having Peculiar Spectra.-In Circular No. 1 i I of the Harvard College Observatory, Prof. Pickering gives a list and details of twenty-four stars which, from a study of the Henry Draper memorial photographs, Mrs. Fleming has found to have " peculiar" spectra.

One or two of the objects call for special remark. The star D.M. $+21^{\circ} 1609$ is identical with N.G.C. 2392, which was found to have a continuous spectrum, with three bright lines, by Wenlock and Peirce on January 7, I869. D'Arrest, also, found it to be gaseous. Photographs taken at Harvard on November 21, 1900, and November 27, I905, show no traces of the bright lines characteristic of gaseous nebulæ, but that its spectrum is of the fourth type. This star is in Gemini, its approximate right ascension and declination (for 1900) being $7 \mathrm{~h} .23 .3 \mathrm{~m}$. and $+2 I^{\circ} 7^{\prime}$ respectively.

In the spectrum of the star D.M. $+36^{\circ} 3907$ the hydrogen line $H \beta$ appears as a fine bright line centrally superposed on a dark line, on photographs taken on July 4 and November 4, 1905 .

A spectrogram of the variable star $R$ Cygni, obtained on November 19, 1890, showed the hydrogen lines $\mathrm{H}_{\gamma}$ and $\mathrm{H} \delta$ bright, but a photograph taken on December 7, I904, with the same instrument, shows a spectrum of the fourth type containing no trace of bright hydrogen lines.

The Lunar Eclipse of February 8.--The total eclipse of the moon which took place on February 8 this year was fully observed at the Goodsell Observatory, Northfield, Minn. (U.S.A.), and an account of the observations is given in No. 3, vol. xiv., of Popular Astronomy.

Dr. Wilson especially remarks on the brightness of the eclipsed moon, and on the remarkable contrasts of colour seen on the darkened surface.

Five photographs were secured, and the last one, taken with a small camera attached to the telescope, exposure $5 \mathrm{~m}$., shows the details of the lunar surface and its unequal colouring very plainly.

Similar obscrvations were made by $M$. Quenisset at the Nanterre Observatory, and four of his photographs are reproduced in the March number of the Bulletin de la Société astronomique de France. He records the shadow as "very transparent."

NO. I9OI, VOL: 73]

\section{PARALLEL RUNNING OF ALTERNATE CURRENT GENERATORS.} $\mathrm{HE}$ Bulletin des Séances de la Société française de
Physique for the second quarter of last year contains an interesting article by M. Boucherot on the general principles which enter into the design and construction of alternating current generators.

After a brief description of the present methods of construction, the author passes on to consider, first, the wave form; secondly, the regulation; thirdly, parallel running; and, finally, methods of compounding.

The most important part of the article is that devoted to the question of parallel running, and, although the mathematical treatment is not verr clearly explained, the conclusions arrived at are interesting.

The question is considered under two headings. In each the subject of inquiry is the influence of the fly-wheel, or the fly-wheel effect of the rotating parts, on the oscillations about a state of uniform angular velocity; but under the first heading the oscillations are caused by the variations of turning effort of the prime mover during a single revolution, and under the second heading the oscillations are produced by the action of the engine governor.

In dealing with the first of these there are two quantities which are of prime importance in the calculations viz. the energy stored in the rotating parts, $W\left(=\frac{1}{2} J \Omega^{2}\right)$, and the elastic couple or restoring force, $\mathrm{C}_{s}$, which is defined as the couple which tends to restore the rotating parts to phase coincidence with the network to which the armature is connected, when the deviation is one radian. Then it is shown that the natural period of the system is $2 \pi \sqrt{\mathrm{J} / \mathrm{C}_{s}}$, and the restoring force $\mathrm{C}_{s}=\mathrm{C}_{\mathrm{x}} p k$, where $\mathrm{C}_{\mathrm{N}}$ is the full load torque, $p$ the number of pairs of poles, and $k$ the ratio of the short-circuit current to the normal current.

Next, the analysis of the turning moment is given for single-cylinder and for multiple-cylinder engines as follows :-

\begin{tabular}{|c|c|c|c|c|c|c|c|}
\hline \multirow{2}{*}{\multicolumn{2}{|c|}{ Single cylinder }} & \multicolumn{3}{|c|}{ Order of harmonic } & \multicolumn{2}{|l|}{ Half load } & \multirow{2}{*}{$\begin{array}{c}\text { Full load } \\
\text { O I } 4\end{array}$} \\
\hline & & $\cdots$ & 1 & $\ldots$ & 0.12 & $\ldots$ & \\
\hline ," & ," & $\ldots$ & 2 & $\ldots$ & 0.9 & $\ldots$ & ० 9 \\
\hline , & ," & $\ldots$ & 3 & $\ldots$ & 0.12 & $\ldots$ & 0.11 \\
\hline & & $\cdots$ & 4 & $\ldots$ & 0.4 & $\ldots$ & $0.1 \mathrm{I}$ \\
\hline Multip & cylinder & & I & $\cdots$ & 0.1 & $\ldots$ & 0.1 \\
\hline " & ", & $\ldots$ & 2 & $\cdots$ & 0.5 & $\cdots$ & 0.2 \\
\hline , & , & $\cdots$ & 3 & $\cdots$ & 0.35 & $\cdots$ & 015 \\
\hline
\end{tabular}

the mean constant turning moment being reckoned as unity.

Each harmonic produces its own oscillation in the rotating system, the amplitude of which is proportional to the value of the harmonic multiplied by $\frac{\mathrm{I} / 2 n^{2}}{\mathrm{~W}-\mathrm{W}_{n}}$ (not $\mathrm{W} / \mathrm{W}-\mathrm{W}_{n}$ as stated in the original), where $n$ is the order of the harmonic and $\mathrm{W}_{n}=\mathrm{C}_{s} / 2 n^{2}$. If the total fly-wheel effect happens to be such that $W=W_{n}$, resonance will occur, and this expression will enable the designer to proportion the rotating parts so as to avoid serious trouble.

More interesting is that part of the article devoted to the effect of the engine governor on parallel running and hunting. The subject is confessedly a difficult one, and at present there is no accepted theory. The suggestion put forward by the author is somewhat compressed and difficult to follow; and, even so, only the chief points of the argument can be mentioned here.

The generating set with its governor is treated as being composed of two interdependent oscillating systems, each with its own natural period and its own coefficient of damping. In addition to these four quantities, two others are of great importance, viz. $K$, the percentage variation of speed between no load and full load, and $1_{d}$, the time lag of the governor. The latter quantity is defined as the time which elapses between the governor reaching its extreme position and the turning moment of the engine taking up its corresponding value. This time lag is greater in compound and triple expansion than in simple engines, due to the passage of the steam through the cylinders.

Considering, first, the case of a generating set connected to an external network assumed to be of infinite capacity, it 
is shown that the periodicity of the oscillation is given by the equation

$$
\tan \left(\alpha . \mathrm{T}_{d}\right)=\mathrm{I} / 2 m\left(\alpha_{r} / \alpha-\alpha / \alpha_{r}\right),
$$

where $2 \pi / \alpha$ is the period of the oscillations produced, $2 \pi / a_{r}$ is the natural period of the governor, and $m$ is the

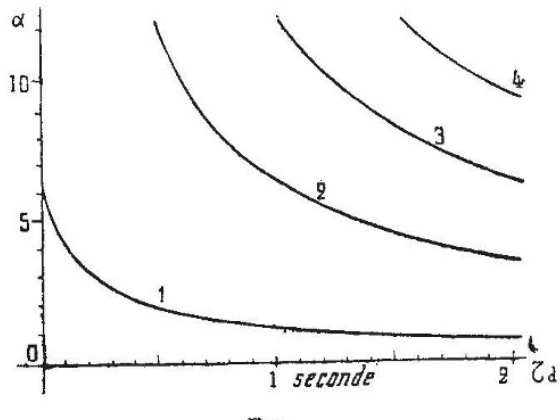

FIG. I.

ratio of the actual damping of the governor to the smallest value of the same coefficient which makes the governor dead beat.

This equation of $a$ in terms of $\mathrm{T}_{d}$ represents a series of curves, some of which give rise to negative values. The positive values corresponding to $m=1$ and $\alpha_{r}=6 \cdot 32$ are

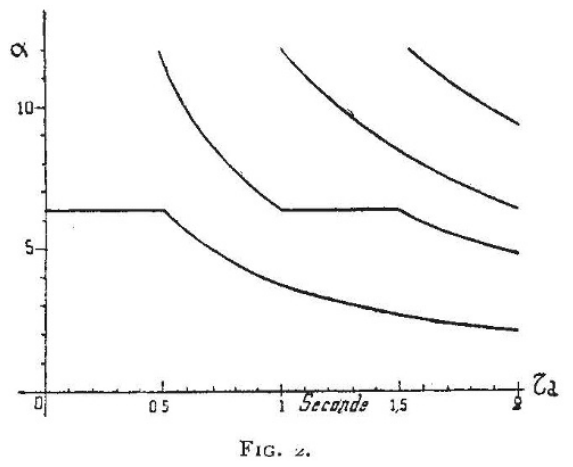

shown in Fig. I. Of these curves, only the lowest one represents oscillations which are not evanescent.

For this case the conclusion is reached that for satisfactory running the percentage variation of speed $\mathrm{K}$ must not be too small, and the fly-wheel effect must be designed in proportion to the time lag of the governor.

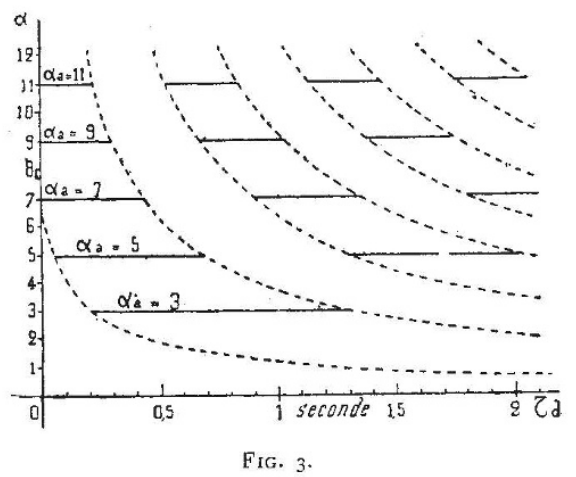

Passing to the case where two sets are working in parallel, the equation giving the frequency of the oscillations is similar to the above, provided the damping in the generators is small. In this case, however, the curves which give positive values of $\alpha$ are quite different, being as shown in Fig. 2. The straight line portions correspond to $a=a_{a}$, where $2 \pi / \alpha_{a}$ is the natural period of the alternator.

Now the rate of subsidence of any oscillation contains a term $\left(x-\alpha / \alpha_{a}\right)$, and it is consequently clear that it would be unsafe to allow any value of $T_{a}$ between 0 and 0.5 , or between $I$ and $x \cdot 5$, as shown in the figure. If, however, the damping of the governor is much greater than the critical dead-beat value, satisfactory working may be possible.

A point of great interest is brought out in this connection, viz. the influence of the fly-wheel effect. The straight portions of the curves in Fig. 2 depend upon the natural period of the alternator, which in turn depends upon the fly-wheel. The heavier the fly-wheel the less the value of $\alpha_{a}$, and consequently the longer the straight portion of the curve as shown in Fig. 3. In other words, the greater the fly-wheel effect the greater will be the range of $\mathrm{T}_{d}$ for which satisfactory working is difficult. From this it would appear that it is quite possible to provide too heavy a flywheel.

The article concludes with a brief reference to the various methods of compounding alternators.

\section{GEOLOGICAL NOTES.}

IN the Zeitschrift der Gesellschaft für Erdkunde zu Berlin (1905, p. 412) Prof. Dr. A. Phillipson, of Bern, outlines his recent journey of ro,ooo kilometres through the west of Asia Minor, including Brussa, near the Sea of Marmora, and Makri, on its Mediterranean inlet in the south. The preliminary results indicate the existence of a "Lydian mass" of granite, gneiss, and crystalline schists, which forms on the whole a hummocky country, flattening itself out where the lower course of the Mrander cuts into it. The inhabitants are mostly clustered along the included basins of Neogene deposits. A zone of metamorphic limestones and less altered phyllites lies outside this mass, following the strike of the bow-shaped crystalline core; and the discovery of a new species of Fusulina (p. 4I7) places part of this outer zone as Permo-Carboniferous. To the south and south-east, the Cainozoic earthmovements have brought up folded limestones of the Cretaceous and Eocene type of Greece and Rhodes. The complete results of the journey will not be worked out for several years.

Dr. G. Steinmann continues, in the Berichte der naturforschenden Gesellschaft zu Freiburg-im-Breisgau for September, 1905, his "Geologische Beobachtungen in den Alpen." The question of Klippen-structure and overfolding in the classical Alps of Glarus leads on to a comparison with the eastern Alps. The author gives a valuable exposition of Schardt's views, which were published in 1893 , and which led to the conception of the breaking up of an overthrust limestone mass into blocks or "klippen," which lie discordantly among later sediments. Without going so far as Termier (p. 32), Dr. Steinmann sees in this striking theory of overfolding the true explanation of the phenomena of the Bündnerschiefer and the limestone zone, and he appeals to workers in the eastern Alps to consider'Schardt's views at least in the light of a scientific possibility. The last part of the present paper includes a bold but reasonable speculation as to the connection between deep-sea radiolarian deposits and diabasic igneous rocks. It is suggested, for the Alpine, Scotch, and other instances, that these basic igneous masses accumulated under the oceanfloors, just as more highly silicated rocks are believed to gather under continents. Consequently, a deep-sea epoch, followed by one of compression and overthrusting, would lead to a squeezing out of " ophiolitic" igneous rocks somewhere along the zone of the radiolarian cherts.

The activity of geological research in the African colonies is evidenced by a recent part of the Transactions of the Geological Society of South Africa, published in Johannesburg in September, i905. Mr. A. L. Hall describes (p. 47) the mode of occurrence of the tin-ore in the picturesque Bushveld area forty miles north-east of Pretoria. The ore was first noticed in the local granite as recently as 1904, and the field was described by H. Merensky in that year. Its exploitation at once followed, and Mr.

NO. I9OI, VOL. 73] 